\title{
Photoreduction and Stabilization Capability of Molecular Weight Fractionated Natural Organic Matter in Transformation of Silver Ion to Metallic Nanoparticle
}

\author{
Yongguang Yin, ${ }^{\dagger}$ Mohai Shen, ${ }^{\dagger}$ Xiaoxia Zhou, ${ }^{\dagger}$ Sujuan Yu, ${ }^{\dagger}$ Jingbo Chao, ${ }^{\ddagger}$ Jingfu Liu, ${ }^{*}{ }^{\dagger}$ and Guibin Jiang ${ }^{\dagger}$ \\ ${ }^{\dagger}$ State Key Laboratory of Environmental Chemistry and Ecotoxicology, Research Center for Eco-Environmental Sciences, Chinese \\ Academy of Sciences, Beijing 100085, China \\ ${ }^{\ddagger}$ Chemical Metrology and Analytical Science Division, National Institute of Metrology, Beijing 100013, China
}

Supporting Information

\begin{abstract}
Photoinduced reduction of silver ion $\left(\mathrm{Ag}^{+}\right)$to silver nanoparticles (AgNPs) by dissolved organic matter (DOM) plays a crucial role in the transformation and transport of engineered AgNPs and $\mathrm{Ag}^{+}$in aquatic environments. DOM is a mixture of natural polymers with wide molecular weight (MW) distribution, and the roles of specific components of DOM in the photoreduction of $\mathrm{Ag}^{+}$to AgNPs are still not understood. In this study, MW fractionated natural organic matter $\left(\mathrm{M}_{\mathrm{f}} \mathrm{NOM}\right)$ were investigated for their roles on the photoreduction process and stabilization of the formed AgNPs. This photoinduced reduction process depends highly on $\mathrm{pH}$, concentration of $\mathrm{Ag}^{+}$and NOM, light quality, and the $\mathrm{MW}$ of $\mathrm{M}_{\mathrm{f}}-\mathrm{NOM}$. Monochromatic radiation and light attenuation correction suggested that the difference of $\mathrm{M}_{\mathrm{f}} \mathrm{NOM}$ on reduction was mainly ascribed to the

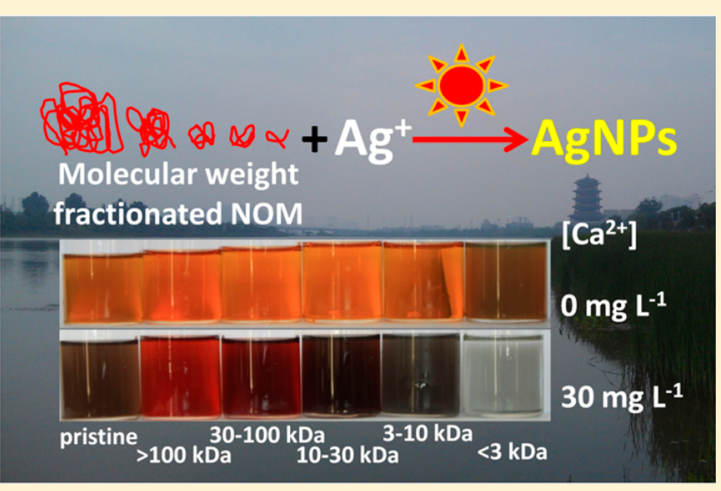
differential light attenuation of $\mathrm{M}_{\mathrm{f}} \mathrm{NOM}$ rather than the "real" reductive ability. More importantly, compared with low MW fractions, the high MW $\mathrm{M}_{\mathrm{f}} \mathrm{NOMs}$ exhibit drastically higher capability in stabilizing the photosynthesized AgNPs against $\mathrm{Ca}^{2+}$-induced aggregation. This finding is important for a better understanding of the differential roles of $\mathrm{M}_{\mathrm{f}} \mathrm{NOM}$ in the transformation and transport of $\mathrm{Ag}^{+}$and engineered AgNPs in DOMrich surface water.
\end{abstract}

\section{INTRODUCTION}

With the progress of nanotechnology, more and more nanotechnology-based consumer products are involved into people's daily life. According to the data from a recent report, "Project on Emerging Nanotechnologies," the nanotechnology consumer products inventory contained 1628 products or product lines in 2013, in which consumer products containing silver nanomaterials accounted for over $23 \%{ }^{1}$ Silver nanoparticles (AgNPs), well-known for their broad-spectrum antimicrobial properties, have many applications in consumer products, including textiles, food packaging, cosmetics, medical devices, and household appliances. ${ }^{2}$ In producing, using, washing, and disposing of AgNPs and their products, AgNPs could inevitably enter surrounding environments. ${ }^{3-7}$ As demonstrated recently, AgNPs are toxic to microorganisms, algae, plants, invertebrates, vertebrates and human cell lines. ${ }^{8}$ Thus, the widespread use and potential toxicity of AgNPs to various organisms and humans have led to concerns about their safety.

The transformation of different silver species in natural environments plays a crucial role on the stability, transport, and toxicity of AgNPs. ${ }^{8}$ Unlike other persistent toxic substances, AgNPs are highly dynamic and prone to transform into other silver species in natural environments. ${ }^{9-12}$ It is known that both metallic silver and silver ion $\left(\mathrm{Ag}^{+}\right)$are not thermodynamically stable under environmental conditions. ${ }^{8}$ Metallic AgNPs could be oxidized by dissolved $\mathrm{O}_{2}$ and release $\mathrm{Ag}^{+}$in aquatic environments, a process that is highly dependent on the size of AgNPs and the $\mathrm{pH}$ of the solution. ${ }^{13}$ Although the effect of size also plays an important role in the uptake and toxicity of AgNPs, ${ }^{14,15}$ the acute toxicity of AgNPs has been mainly ascribed to the released $\mathrm{Ag}^{+} .{ }^{16}$ In natural waters, dissolved $\mathrm{Ag}^{+}$ could additionally be rereduced to metallic AgNPs by dissolved organic matter $(\mathrm{DOM})^{17-20}$ or extracellular polymer substances. $^{21,22}$ Our previous study demonstrated that in natural surface water $\mathrm{Ag}^{+}$could convert to AgNPs under sunlight by DOM. $^{18}$ In this process, a phenol group in DOM transfers one electron to dissolved $\mathrm{O}_{2}$ to form a superoxide radical, ${ }^{23}$ and this superoxide subsequently reduces $\mathrm{Ag}^{+}$to AgNPs. ${ }^{24}$ Another study suggested $\mathrm{Ag}^{+}-\mathrm{NOM}$ complexation also plays a crucial role in this reduction process. ${ }^{20}$ The reduction of $\mathrm{Ag}^{+}$to AgNPs

Received: April 24, 2014

Revised: July 16, 2014

Accepted: July 22, 2014

Published: July 22, 2014 
by DOM possibly improves the persistence of AgNPs in sunlit DOM-rich aqueous environments ${ }^{18}$ and has crucial impact on the toxicity of AgNPs to organisms. ${ }^{21}$ However, DOM is a complex polydispersed mixture of natural polymers, with molecular weights (MW) ranging from less than $100 \mathrm{Da}$ to over $300 \mathrm{kDa}$, 25 and it is still unknown which components of $\mathrm{DOM}$ are mainly responsible for the reduction of $\mathrm{Ag}^{+}$and stabilization of the resulting AgNPs. Different MW fractionated DOM differ greatly in chemical composition, ${ }^{26}$ acidity, ${ }^{27}$ adsorption, ${ }^{28}$ binding, ${ }^{29,30}$ and reaction behaviors. ${ }^{31-33}$ Carboxylic groups were found to be concentrated in low MW fractions of humic acids (HA), while polysaccharides and peptides were in high MW fractions. ${ }^{22,30}$ The difference among MW fractions of HA could further induce the difference of photochemical properties. $^{34-36}$ For example, the photoreduction of Fe(III) and $\mathrm{Cr}(\mathrm{VI})$ highly depends on the MW of DOM, with low MW DOM is the major driver for photoreduction. ${ }^{33,36}$

The overall objective of this study was to investigate the effect of MW fractionated natural organic matter $\left(\mathrm{M}_{\mathrm{f}} \mathrm{NOM}\right)$ on the reduction of $\mathrm{Ag}^{+}$into AgNPs in water and to understand the effects of $\mathrm{M}_{\mathrm{f}} \mathrm{NOM}$ on the morphology and stabilization of photosynthesized AgNPs in the presence of $\mathrm{Ca}^{2+}$. To this end, Suwannee River Natural Organic Matter (SRNOM) was selected as model DOM, and the reductive kinetics of $\mathrm{Ag}^{+}$by $\mathrm{M}_{\mathrm{f}}-\mathrm{NOMs}$ and pristine SRNOM were studied and compared under simulated sunlight and heating. This work is helpful to understand the fate of highly dynamic AgNPs and other ionic silver species and their interaction with DOM in surface waters.

\section{MATERIALS AND METHODS}

Materials. SRNOM (Lot No. 1R101N) was obtained from the International Humic Substance Society (St. Paul, MN). Stock solutions were prepared at $1.0 \mathrm{~g} \mathrm{~L}^{-1}$ in deionized water and shaken on a rotator overnight at room temperature. $\mathrm{AgClO}_{4}$ was purchased from Beijing Chemicals (Beijing, China). Amicon Ultra-15 centrifugal filter (with $3 \mathrm{kDa}, 10$ $\mathrm{kDa}, 30 \mathrm{kDa}$, and $100 \mathrm{kDa}$ nominal $\mathrm{MW}$ cutoff, respectively) from Millipore (Darmstadt, Germany) were used for fractionation of SRNOM.

UV films, purchased from Energy-Film (Portland, Oregon), were used as UV-block film. Mylar films, purchased from United States Plastic Corp. (Lima, Ohio), were defined as UVB-block film. Aluminum foil was purchased from Cleanwrap (Shanghai, China). Transmittance of light through these films or aluminum foil is shown in Supporting Information (S) Figure S1.

NOM Fractionation. The Amicon Ultra-15 centrifugal filters were initially rinsed with deionized water thoroughly to remove glycerol. Next, the stock solution of SRNOM was loaded into the $100 \mathrm{kDa}$ filter and centrifuged for $30 \mathrm{~min}$ at $3743 g$ by a Sigma $3-18 \mathrm{~K}$ centrifuge (St. Louis, MO). The filtrate was collected and then further filtered sequentially by 30 $\mathrm{kDa}, 10 \mathrm{kDa}$ and $3 \mathrm{kDa}$ filters. The centrifuging rates for 30 $\mathrm{kDa}, 10 \mathrm{kDa}$ and $3 \mathrm{kDa}$ filter were 5095, 6654, and $8422 \mathrm{~g}$, respectively. The retentate was then washed with deionized water and collected as $\mathrm{M}_{\mathrm{f}} \mathrm{NOM}$ (>100 kDa, 30-100 kDa, 10$30 \mathrm{kDa}, 3-10 \mathrm{kDa}$, respectively). The filtrate after $3 \mathrm{kDa}$ filter treatment was collected as $<3 \mathrm{kDa} \mathrm{M}_{\mathrm{f}} \mathrm{NOM}$.

Characterization of Pristine and $M_{f}-N O M$. Concentrations of pristine SRNOM and $\mathrm{M}_{\mathrm{f}} \mathrm{NOM}$ were measured on a Teledyne Tekmar Total Organic Carbon (TOC) Fusion Analyzer (Mason, OH). The MW distribution of $\mathrm{M}_{\mathrm{f}} \mathrm{NOM}$ fraction is shown in SI Figure S2. The total recovery of TOC was $69.2 \%$. Potential losses of NOM could have occurred during the washing procedure or by adsorption onto the filter membrane. ${ }^{30}$ Five $\mathrm{mg} \mathrm{L}^{-1}$ dissolved organic carbon (DOC) of pristine- or $\mathrm{M}_{\mathrm{f}} \mathrm{NOMs}$ were prepared in deionized water and

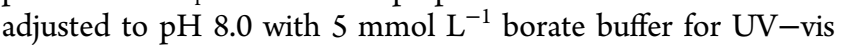
and fluorescence spectroscopic characterization. UV-vis spectra were recorded on a Shimadzu UV-vis-NIR Spectrophotometer (UV-3600, Japan). Fluorescence excitationemission matrices were measured by a Horiba spectrophotometer (FluoroMax-4, Edison, NJ) with a $1 \mathrm{~cm}$ quartz cuvette. Emission was measured from 280 to $600 \mathrm{~nm}$ in $2 \mathrm{~nm}$ increments, at excitation wavelengths of 200 to $450 \mathrm{~nm}$ in $5 \mathrm{~nm}$ increments, with both excitation and emission slit widths $5 \mathrm{~nm}$. The fluorescence inner-filtering effect was corrected by UV-vis absorbance spectra of the identical NOM solution.

Photoinduced Reduction of $\mathrm{Ag}^{+}$to AgNPs. The experiments were performed in $100 \mathrm{~mL}$ quartz glass bottles with quartz caps. The simulated sunlight was provided by a solar simulator (TEMI880, Beifang Lihui, Beijing, China) equipped with three wind-refrigerated $2500 \mathrm{~W}$ Xe lamp. The spectrum of the simulated sunlight was measured by a miniature fiber optic spectrometer (USB2000, 2E7909, OceanOptics Inc., Dunedin, FL) with wavelength from 339 to 1027 $\mathrm{nm}$ (SI Figure S3a). The intensity of the light was set as $400 \mathrm{~W}$ $\mathrm{m}^{-2}$. During the experiment, the reaction temperature was maintained at $\sim 35{ }^{\circ} \mathrm{C}$. The total volume of the solution was $100 \mathrm{~mL}$. Five mmol L $\mathrm{L}^{-1}$ borate was used to buffer the solution. Three $\mathrm{mL}$ solution was sampled at specific time intervals for UV-vis spectrometry and transmission electron microscope (TEM) characterization. Considering the repeatability and reproducibility of the photoreduction process and UV-vis spectrometry, we performed each test in one sample without duplication for UV-visible spectroscopy characterization. The $\mathrm{pH}$, concentrations of $\mathrm{Ag}^{+}$and $\mathrm{NOM}$, and concentration of $\mathrm{Ca}^{2+}\left(\right.$ as $\left.\mathrm{Ca}\left(\mathrm{ClO}_{4}\right)_{2}\right)$ were investigated during photoreduction of $\mathrm{Ag}^{+}$to AgNPs.

The effect of light quality was investigated by covering the quartz bottle with aluminum foil, UV-block film, and UV-Bblock film, and the resulting solutions were defined as "dark" (covered with aluminum foil), "Full radiation" (without covering), "UV-A+ Visible" (covered with UV-B-block film) and "Visible only" (covered with UV-block film).

The essential reductive abilities of $\mathrm{M}_{\mathrm{f}}-\mathrm{NOMs}$ on $\mathrm{Ag}^{+}$to AgNPs were further evaluated at a high concentration of NOM (0.4 $\mathrm{mmol} \mathrm{L}^{-1} \mathrm{AgClO}_{4}, 20 \mathrm{mg} \mathrm{L}^{-1}$ DOC NOM). The monochromatic irradiation $(366 \mathrm{~nm})$ was provided with a rotating turntable, merry-go-round photoreactor (XPA, Xujiang Electromechanics, Nanjing, China) adapted with glass filters to isolate the $366 \mathrm{~nm}$ light from the $\mathrm{Hg}$ lamp and with a medium pressure $\mathrm{Hg}$ vapor lamp $(100 \mathrm{~W})$ in the center. The spectrum of light source was also measured by a miniature fiber optic spectrometer (USB2000, 2E7909, OceanOptics Inc., Dunedin, FL) (SI Figure S3b and c). In addition, the transmittance of light through glass filter is shown in SI Figure S4, demonstrating that the glass filter could effectively separate $366 \mathrm{~nm}$ light from $\mathrm{Hg}$ lamp. The experiments were performed in $50 \mathrm{~mL}$ quartz tubes with quartz caps $(50 \mathrm{~mL}, 2.2 \mathrm{~cm}$ diameter) and reaction temperature was maintained at $\sim 10{ }^{\circ} \mathrm{C}$ by thermostatic water-bath (CHD-0515, Boyuan Analytical Instrument, Changzhou, China).

Ultrafiltration coupled with inductively coupled plasma mass spectrometry (ICP-MS) (7700ce, Agilent, Santa Clara, CA) was used to determine $\mathrm{Ag}^{+}$and AgNPs in the photosynthesized 
AgNPs solution. Briefly, $1 \mathrm{~mL}$ photosynthesized AgNPs solution, $4 \mathrm{~mL}$ deionized water and $5 \mathrm{~mL}$ of saturated $\mathrm{Na}_{2}$ EDTA, were added into the Amicon Ultra-15 centrifugal filter (with $3 \mathrm{kDa}$ nominal MWCO) (Millipore, Darmstadt, Germany). After centrifugation at $9600 \mathrm{rpm}$ for $40 \mathrm{~min}$, the filtrate was diluted by $5 \% \mathrm{HNO}_{3}$ for $\mathrm{Ag}^{+}$determination by ICPMS. The concentration of AgNPs was calculated by subtracting $\mathrm{Ag}^{+}$concentration from the total silver concentration, which was determined by ultrafiltration-ICP-MS. Here, $\mathrm{Na}_{2}$ EDTA was added to complex with $\mathrm{Ag}^{+}$and facilitate the separation of $\mathrm{Ag}^{+}$ and AgNPs. According to previous studies, the dissolution rate of AgNPs by EDTA is quite low and should not influence the determination of $\mathrm{Ag}^{+}$and AgNPs. ${ }^{37-39}$ The recovery of $\mathrm{Ag}^{+}$in ultrafiltration process in the presence of $5 \mathrm{mg} \mathrm{L}^{-1} \mathrm{SRNOM}$ was determined as $98.1 \pm 1.4 \%$. For $\mathrm{Ag}^{+}$and AgNPs determination, a minimum of two samples were measured.

The pseudo-first-order rate equation of ionic $\mathrm{Ag}$ photoreduction is

$$
\frac{d[\mathrm{AgNP}]}{d \mathrm{t}}=k_{\lambda}\left[\mathrm{Ag}^{+}\right]
$$

The apparent formation rate constant $k_{\lambda}$ in the presence of pristine and $\mathrm{M}_{\mathrm{f}}-\mathrm{NOM}$, corrected for light screening effect, is ${ }^{40}$

$$
k_{\lambda, \text { corrected }}=\frac{k_{\lambda}}{S_{\lambda}}=\left(2.303 k_{\lambda} \alpha_{\lambda} l\right) /\left(1-10^{-\alpha_{\lambda} l}\right)
$$

where $k_{\lambda \text {,corrected }}$ is the corrected formation rate constant considering the light screening effect, $S_{\lambda}$. The light screening factor, $\alpha_{\lambda}$, is the decadic absorption coefficient of the solution at $366 \mathrm{~nm}$, and $l$ is the light path length of the reaction cell $(2.2$ $\mathrm{cm})$.

Heat-Induced Reduction of $\mathrm{Ag}^{+}$to AgNPs. The experiments were performed in $100 \mathrm{~mL}$ pressure-tight brown glass bottles. The reaction mixture of $\mathrm{AgClO}_{4}$ and $\mathrm{NOM}$ solution, was incubated at $4{ }^{\circ} \mathrm{C}$ (in a refrigerator), room temperature $\left(\mathrm{RT}, \sim 25{ }^{\circ} \mathrm{C}\right.$ ), $45^{\circ} \mathrm{C}$, and $60{ }^{\circ} \mathrm{C}$ (heated in water thermostatic bath). The reaction was monitored at regular intervals by $\mathrm{UV}$-vis spectroscopy. A $5 \mathrm{mmol} \mathrm{L}^{-1}$ borate $(\mathrm{pH}$ 8.0) was used to buffer the solution.

Characterization of AgNPs. UV-vis spectra were recorded from 200 to $800 \mathrm{~nm}$ on a Shimadzu UV-vis-NIR Spectrophotometer (UV-3600, Japan). Transmission electron microscopy (TEM) images, coupled with an energy dispersive spectrometer (EDS) and selected area electron diffraction (SAED) were obtained from a TEANAI G ${ }^{2} 20-200 \mathrm{kV}$ (FEI, Hillsboro, OR) transmission electron microscope. The specimen for HRTEM was prepared by slow evaporation of solution onto an ultrathin carbon-coated copper grid (T11032, Xinxing Bairui, Beijing, China).

Dynamic light scattering (DLS) measurements were performed on a Zetasizer Nano ZS (Malvern Instruments Ltd., Worcestershire, UK) according to suggested protocol. Briefly, the detector employed a laser source of $633 \mathrm{~nm}$ and detection angle of $173^{\circ}$. Aqueous solutions of AgNPs ( $1.5 \mathrm{~mL}$ ) were analyzed using disposable plastics sizing cuvettes (DTS0012) at $25{ }^{\circ} \mathrm{C}$. Equilibration time was set as $120 \mathrm{~s}$. Three measurements were performed for each sample, with 11 subruns and a $10 \mathrm{~s}$ run duration. The measurement position was optimized automatically by the ZetaSizer.

\section{RESULTS AND DISCUSSION}

Characteristics of Pristine and $\mathrm{M}_{\mathrm{f}}-\mathrm{NOM}$. The prepared $\mathrm{M}_{\mathrm{f}} \mathrm{NOMs}$ were initially characterized by UV-vis spectroscopy and fluorescence excitation-emission spectroscopy (SI Figure S5 and S6). Generally, UV-vis spectra revealed that with increasing MW, the molar absorptivity $(\varepsilon)$ at $280 \mathrm{~nm}$ (SI Table S1) increased significantly, indicating increased abundances of aromatic moiety in higher MW $\mathrm{M}_{\mathrm{f}}$ NOMs. ${ }^{41}$ The Ex/Em and maximum intensity of fluorescence peaks for pristine- and $\mathrm{M}_{\mathrm{f}}$ NOMs are shown in SI Table S1. The Ex/Em of spectra peaks indicate humic-like structures in pristine $\mathrm{NOM}$ and $\mathrm{M}_{\mathrm{f}}-\mathrm{NOM}^{42}$ Additionally, the maximum intensity of fluorescence peaks increased as the $\mathrm{MW}$ of $\mathrm{M}_{\mathrm{f}} \mathrm{NOM}$ decreased, suggesting increased abundances of carboxylic moiety in lower $\mathrm{MW} \mathrm{M}_{\mathrm{f}}$ NOMs. $^{35}$

Photoreduction of $\mathrm{Ag}^{+}$to AgNPs by Pristine and $\mathrm{M}_{\mathrm{f}}$ NOM. The photoreduction of $\mathrm{Ag}^{+}$to AgNPs was initially examined with $0.2 \mathrm{mmol} \mathrm{L}^{-1} \mathrm{AgClO}_{4}$ and $5 \mathrm{mg} \mathrm{L}^{-1} \mathrm{DOC}$ of pristine or $\mathrm{M}_{\mathrm{f}} \mathrm{NOM}$ in borate buffer $(\mathrm{pH}$ 8.0) under simulated sunlight (Xe lamp). In $1 \mathrm{~h}$, the color of solution within $<3 \mathrm{kDa}$ $\mathrm{M}_{\mathrm{f}} \mathrm{NOM}$ turned to a yellow or pale-red color, while solutions within other NOM did not change significantly. This result indicates that the formation rate of AgNPs in $<3 \mathrm{kDa} \mathrm{M}_{\mathrm{f}} \mathrm{NOM}$ is much higher than those of others in this initial stage. An apparent slow induction stage was observed for higher $\mathrm{MW} \mathrm{M}_{\mathrm{f}}$ NOMs. However, with increasing irradiation time, the color deepened for all these samples. The UV-vis spectra (SI Figure S7) showed that a peak was evident at $\sim 400 \mathrm{~nm}$, corresponding to the surface plasma resonance (SPR) absorption of AgNPs. The SPR peak of AgNPs in $<3 \mathrm{kDa}_{\mathrm{f}} \mathrm{NOM}$ was much broader than others and associated with a longer wavelength, indicating polydispersed and larger AgNPs formed in the solution. It should be noted that although UV-vis spectrum can be used as a convenient indicator for the formation and concentration of AgNPs, the accuracy of quantifying the AgNPs by UV-visible spectroscopy is difficult because of the effect of AgNPs size on their SPR. Thus, we further used ultrafiltrationICP-MS to determine the concentration of $\mathrm{Ag}^{+}$in the photoirradiated solution, indicating no significant difference between various NOM for reduction of $\mathrm{Ag}^{+}$(72.8\%-80.2\% reduction of $\mathrm{Ag}$ in pristine and $\mathrm{M}_{\mathrm{f}}-\mathrm{NOM}$ after $29 \mathrm{~h}$ irradiation). The fast reduction of $\mathrm{Ag}^{+}$by $<3 \mathrm{kDa} \mathrm{M}_{\mathrm{f}} \mathrm{NOM}$ in the first several hours (SI Figure S7) is possibly ascribed to the fast nucleation of AgNPs.

Comprehensive characterizations, including TEM, SAED, and EDS, were also performed to validate the formation of AgNPs (SI Figure S8). All characterizations provided conclusive evidence for the formation of AgNPs through the photoreduction of $\mathrm{Ag}^{+}$by pristine and $\mathrm{M}_{\mathrm{f}} \mathrm{NOM}$. TEM images (SI Figure S8a) also revealed a dual-mode distribution of size of AgNPs with large (average diameter $\sim 10.9 \mathrm{~nm}$ ) and small (average diameter $\sim 3.7 \mathrm{~nm}$ ) particles, which have previously been observed in the heat-induced formation of AgNPs in NOM solution. ${ }^{19}$ DLS further confirmed the occurrence of dual-mode distribution of size of nanoparticles in the reaction solution (SI Table S2). From the high resolution TEM (HRTEM), we clearly observed single crystal small AgNPs and polycrystalline larger AgNPs (SI Figure S8b), suggesting a mechanism of reduction-nucleation-growth and fusion. ${ }^{11,43,44}$ The TEM images shown in SI Figure S9 revealed that the AgNPs formed in $<3 \mathrm{kDa} \mathrm{M}_{\mathrm{f}} \mathrm{NOM}$ have larger size than those in $>100 \mathrm{kDa} \mathrm{M}_{\mathrm{f}}-\mathrm{NOM}$, which is consistent with UV-vis 

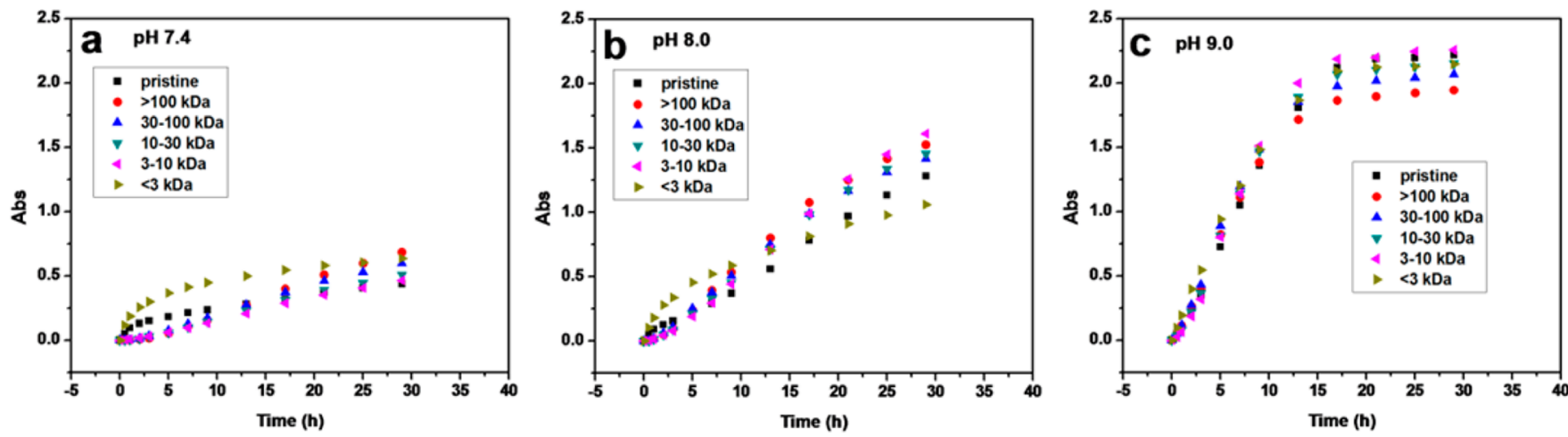

Figure 1. Effect of $\mathrm{pH}$ on the formation of AgNPs from $\mathrm{Ag}^{+}$in the presence of pristine or $\mathrm{M}_{\mathrm{f}} \mathrm{NOM}$ under simulated sunlight irradiation. (a) $\mathrm{pH}$ 7.4, (b) $\mathrm{pH}$ 8.0, (c) $\mathrm{pH}$ 9.0. The absorbance was the maximum absorbance at $\sim 400 \mathrm{~nm}$. Background absorption of NOM was deducted from the prepared AgNPs solution. Solution conditions: $0.2 \mathrm{mmol} \mathrm{L}^{-1} \mathrm{AgClO}_{4}, 5 \mathrm{mg} \mathrm{L}^{-1}$ DOC pristine or $\mathrm{M}_{\mathrm{f}} \mathrm{NOM}, 5 \mathrm{mmol} \mathrm{L}{ }^{-1}$ borate buffer.
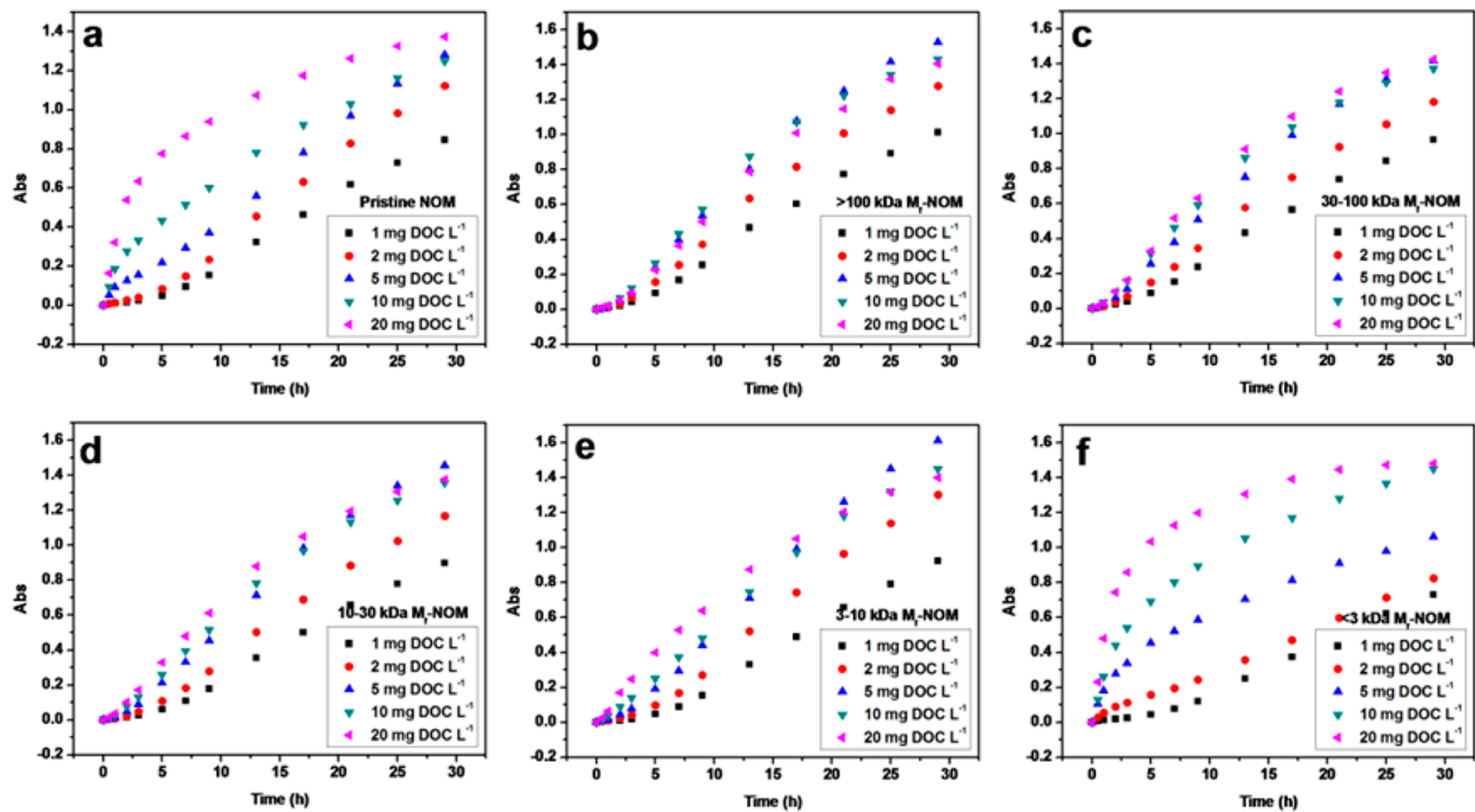

Figure 2. Effect of NOM concentration on the formation of AgNPs from $\mathrm{Ag}^{+}$in the presence of pristine or $\mathrm{M}_{\mathrm{f}} \mathrm{NOM}$ under simulated sunlight irradiation. (a) pristine NOM, (b) $>100 \mathrm{kDa} \mathrm{M}_{\mathrm{f}} \mathrm{NOM}$, (c) 30-100 kDa $\mathrm{M}_{\mathrm{f}}-\mathrm{NOM}$, (d) $10-30 \mathrm{kDa} \mathrm{M}_{\mathrm{f}}-\mathrm{NOM}$, (e) $3-10 \mathrm{kDa} \mathrm{M}_{\mathrm{f}}-\mathrm{NOM}$, (f) $<3 \mathrm{kDa}$ $\mathrm{M}_{\mathrm{f}} \mathrm{NOM}$. The absorbance was the maximum absorbance at $\sim 400 \mathrm{~nm}$. Background absorption of NOM was deducted from the prepared AgNPs solution. Solution conditions: $0.2 \mathrm{mmol} \mathrm{L}^{-1} \mathrm{AgClO}_{4}$ and $5 \mathrm{mmol} \mathrm{L}^{-1}$ borate buffer ( $\mathrm{pH} \mathrm{8.0)}$.

results. This finding suggests that low $\mathrm{MW} \mathrm{M}_{\mathrm{f}} \mathrm{NOM}$ has weaker stabilization capability for AgNPs compared to high $\mathrm{MW} \mathrm{M}_{\mathrm{f}}-\mathrm{NOM}$ in the formation process of AgNPs.

Effect of $\mathrm{pH}$ on Photoreduction of $\mathrm{Ag}^{+}$to AgNPs. Overall, $\mathrm{pH}$ greatly influenced the photoreduction of $\mathrm{Ag}^{+}$to AgNPs by pristine and $\mathrm{M}_{\mathrm{f}} \mathrm{NOM}$, as shown in Figure 1. This $\mathrm{pH}$-dependent photoreduction has been observed in previous studies, ${ }^{18,20}$ mainly caused by the $\mathrm{pH}$-dependent reductive potential of NOM. With an increase of $\mathrm{pH}$, the reductive potential of NOM increases linearly, resulting in a higher formation rate of AgNPs. ${ }^{18}$ Also, the SPR peak shifts to a shorter wavelength (from $426 \mathrm{~nm}$ at $\mathrm{pH} 7.4$ to $402 \mathrm{~nm}$ at $\mathrm{pH}$ 9.0 for $<3 \mathrm{kDa} \mathrm{M} \mathrm{f}_{\mathrm{f}} \mathrm{NOM}$, and from $415 \mathrm{~nm}$ at $\mathrm{pH} 7.4$ to 408 $\mathrm{nm}$ at $\mathrm{pH} 9.0$ for $>100 \mathrm{kDa} \mathrm{M}_{\mathrm{f}} \mathrm{NOM}$ ) (SI Figure S10), indicating the formation of smaller AgNPs. ${ }^{45,46}$ This impact of
$\mathrm{pH}$ on the size of AgNPs is more significant for low $\mathrm{MW} \mathrm{M}_{\mathrm{f}}$ NOM. TEM images (SI Figure S11) clearly show that with the increase of $\mathrm{pH}$ from 7.4 to 8.0, the size of AgNPs formed in $<3$ $\mathrm{kDa} \mathrm{M}_{\mathrm{f}}-\mathrm{NOM}$ solution significantly decreased. The smaller size of formed AgNPs at higher $\mathrm{pH}$ is ascribed to the dissociation of phenolic and carboxyl group, ${ }^{47}$ which result in better dispersion of AgNPs by NOM. The more significant impact of $\mathrm{pH}$ on AgNPs size formed in low MW $\mathrm{M}_{\mathrm{f}} \mathrm{NOM}$ solution is possibly due to the abundance of carboxylic moiety in lower $\mathrm{MW} \mathrm{M}_{\mathrm{f}}$ NOMs.

Effect of Concentration of $\mathrm{Ag}^{+}$and NOM on Photoreduction of $\mathrm{Ag}^{+}$to AgNPs. Effect of $\mathrm{Ag}^{+}$concentration on the formation of AgNPs was investigated in the concentration range of $0-0.5 \mathrm{mmol} \mathrm{L}^{-1} \mathrm{Ag}^{+}$(SI Figure S12). When there is only NOM in the solution (without $\mathrm{Ag}^{+}$), no formation of 
AgNPs was observed (SI Figure S13). In addition, no significant photodegradation of pristine and $\mathrm{M}_{\mathrm{f}} \mathrm{NOM}$ was evident (SI Figure S13). With increasing $\mathrm{Ag}^{+}$concentration, the formation of AgNPs increased accordingly (SI Figure S12), consisted with a pseudo-first-order reaction kinetics to $\mathrm{Ag}^{+} .{ }^{18}$

The AgNPs formation rate was further examined as a function of NOM concentration ranging from 1 to $20 \mathrm{mg} \mathrm{L}^{-1}$ DOC (Figure 2 and SI Figure S14). No formation of AgNPs was observed in $\mathrm{AgClO}_{4}$ solution without NOM. With NOM present, increased formation of AgNPs was observed, but no linear relationship was found between the formation rate of AgNPs and concentration of NOM, especially at higher NOM concentration. As NOM has intense light absorption in the $\mathrm{UV}$-vis region, this observed leveling-off phenomenon of the formation rate was possibly caused by the light attenuation of NOM. $^{20}$ This speculation was further supported by photoreduction of $\mathrm{Ag}^{+}$by $\mathrm{M}_{\mathrm{f}} \mathrm{NOM}$ at different NOM concentrations. At $1 \mathrm{mg} \mathrm{L}^{-1} \mathrm{DOC}$ of $\mathrm{M}_{\mathrm{f}}-\mathrm{NOM}$, the difference in the reductive ability of $\mathrm{M}_{\mathrm{f}} \mathrm{NOM}$ was not significant (SI Figure S14). However, with increased $\mathrm{M}_{\mathrm{f}} \mathrm{NOM}$ concentration to 20 $\mathrm{mg} \mathrm{L}^{-1} \mathrm{DOC}$, reduction of $\mathrm{Ag}^{+}$by pristine and low $\mathrm{MW} \mathrm{M}_{\mathrm{f}}$ NOM increased significantly expand the difference (SI Figure S14), owning to the minor light attenuation of pristine and low MW $\mathrm{M}_{\mathrm{f}} \mathrm{NOM}$ than high MW $\mathrm{M}_{\mathrm{f}} \mathrm{NOM}$.

The light attenuation effect of NOM on AgNP formation was further demonstrated by using a monochromatic radiation (366 $\mathrm{nm}$ ). The UV-vis spectra (SI Figure S15) showed a stronger and broader SPR absorption of AgNPs in $<3 \mathrm{kDa} \mathrm{M}_{\mathrm{f}}$ NOM solution than in other $\mathrm{M}_{\mathrm{f}} \mathrm{NOMs}$, suggesting enhanced AgNPs formation in $<3 \mathrm{kDa} \mathrm{M}_{\mathrm{f}} \mathrm{NOM}$ solution. $\mathrm{Ag}^{+}$and AgNPs determination by ultrafiltration-ICP-MS also confirmed that the formation rate of AgNPs in $<3 \mathrm{kDa} \mathrm{M}_{\mathrm{f}} \mathrm{NOM}$ solution (0.200 $\left.\mathrm{h}^{-1}\right)$ is much higher than other $\mathrm{M}_{\mathrm{f}}$-NOMs $\left(0.101-0.118 \mathrm{~h}^{-1}\right)$ (Table 1). However, as shown in Table 1, after corrected the

Table 1. Formation Rate Constants of AgNPs $\left(k_{\lambda}\right)$ and Corrected Formation Rate Constants of AgNPs $\left(k_{\lambda, \text { corrected }}\right)$ under 366 nm Irradiation $^{a}$

\begin{tabular}{lcccc}
\multicolumn{1}{c}{$\mathrm{M}_{\mathrm{f}} \mathrm{NOM}$} & $\alpha_{\lambda}$ & $S_{\lambda}$ & $k_{\lambda}\left(\mathrm{h}^{-1}\right)$ & $k_{\lambda, \text { corrected }}\left(\mathrm{h}^{-1}\right)$ \\
$>100 \mathrm{kDa}$ & 0.680 & 0.281 & 0.101 & 0.360 \\
$30-100 \mathrm{kDa}$ & 0.583 & 0.321 & 0.109 & 0.340 \\
$10-30 \mathrm{kDa}$ & 0.475 & 0.378 & 0.118 & 0.313 \\
$3-10 \mathrm{kDa}$ & 0.373 & 0.449 & 0.116 & 0.258 \\
$<3 \mathrm{kDa}$ & 0.226 & 0.595 & 0.200 & 0.335
\end{tabular}

${ }^{a}$ Solution conditions: $0.4 \mathrm{mmol} \mathrm{L}^{-1} \mathrm{AgClO}_{4}, 20 \mathrm{mg} \mathrm{L}^{-1} \mathrm{DOC} \mathrm{M}_{\mathrm{f}}$ NOM, $5 \mathrm{mmol} \mathrm{L}^{-1}$ borate buffer ( $\mathrm{pH} 8.0$ ) under $366 \mathrm{~nm}$ irradiation.

light attenuation effect of NOM, the corrected formation rate constants of AgNPs $\left(k_{\lambda, \text { corrected }}\right)$ in the presence of $\mathrm{M}_{\mathrm{f}} \mathrm{NOM}$ are quite similar, demonstrating the lower apparent formation rate constants of AgNPs $\left(k_{\lambda}\right)$ in higher MW $\mathrm{M}_{\mathrm{f}} \mathrm{NOM}$ solutions are mainly ascribed to their stronger light attenuation effect than that of the lower MW $\mathrm{M}_{\mathrm{f}} \mathrm{NOMs}$.

Effects of Light Quality on the Photoreduction of $\mathrm{Ag}^{+}$ to AgNPs. Effects of simulated light quality on the photoreduction of $\mathrm{Ag}^{+}$to AgNPs are shown in SI Figure S16. While there is minor formation of AgNPs under dark conditions, significant formation of AgNPs was observed in NOM solutions exposed to full simulated sunlight, "UV-A+Visible" and "Visible only". Considering the transmittance of UV-block film in visible region is $\sim 80 \%$ (SI Figure S1), the difference of formation rate of AgNPs between "Full radiation" and "UV-A
+Visible" is not significant (SI Figure S16), indicating UV-B in Xe lamp plays a minor role in the reduction of $\mathrm{Ag}^{+}$to AgNPs. SI Figure S16 also showed that both UV-A and visible light play important roles in the photoreduction, with visible light as the primary driver in this reduction process.

Effect of $\mathrm{Ca}^{2+}$ on Photoreduction of $\mathrm{Ag}^{+}$to $\mathrm{AgNPs}$ and the Stability of Photoinduced AgNPs. $\mathrm{Ca}^{2+}$ is ubiquitous in natural waters, with concentration ranging from several $\mathrm{mg} \mathrm{L}^{-1}$ to over $100 \mathrm{mg} \mathrm{L}^{-1}$. It has been well demonstrated that $\mathrm{Ca}^{2+}$ could induce the aggregation of AgNPs while NOM could enhance the stability of AgNPs against aggregation. ${ }^{48,49}$ Recently, study further revealed that high $\mathrm{MW} \mathrm{M}_{\mathrm{f}} \mathrm{NOM}$ provided significantly better stability of gold nanoparticles than low MW $\mathrm{M}_{\mathrm{f}} \mathrm{NOM}^{30}$ We then assumed that $\mathrm{M}_{\mathrm{f}} \mathrm{NOM}$ would also behave differently on the aggregation of AgNPs in the presence of $\mathrm{Ca}^{2+}$. Thus, it is expected that the difference of AgNPs aggregation in different $\mathrm{M}_{\mathrm{f}} \mathrm{NOM}$ solutions will influence the formation and growth of AgNPs. Figure 3

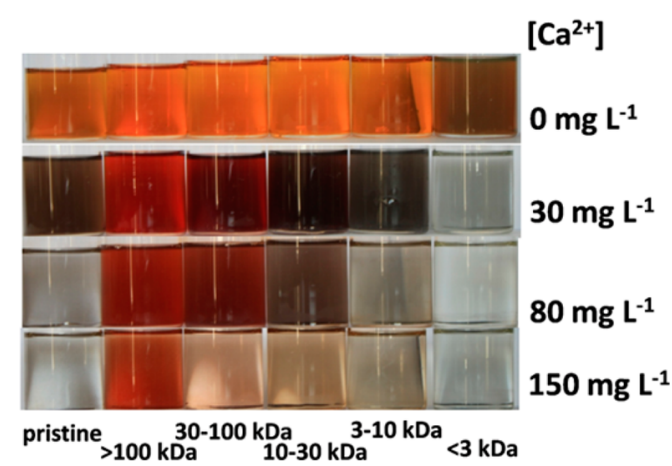

Figure 3. Photography of photoinduced AgNPs solution in the presence of pristine or $\mathrm{M}_{\mathrm{f}} \mathrm{NOM}$ and $\mathrm{Ca}^{2+}$. Reaction conditions: 0.2 $\mathrm{mmol} \mathrm{L}^{-1} \mathrm{AgClO}_{4}, 5 \mathrm{mg} \mathrm{L}^{-1}$ DOC pristine or $\mathrm{M}_{\mathrm{f}} \mathrm{NOM}, 5 \mathrm{mmol} \mathrm{L}$ borate buffer ( $\mathrm{pH} 8.0)$ under simulated sunlight for $29 \mathrm{~h}$.

shows the impact of $0-150 \mathrm{mg} \mathrm{L}^{-1} \mathrm{Ca}^{2+}$ on the photoreduction of $\mathrm{Ag}^{+}$to AgNPs in pristine and $\mathrm{M}_{\mathrm{f}} \mathrm{NOM}$ solutions at the end of a 29-h-exposure. It is clear that the tint of AgNPs solution in the presence of identical NOM turned from yellow to red, then to black, with increasing $\mathrm{Ca}^{2+}$ concentration. High concentration of $\mathrm{Ca}^{2+}$ also induced sedimentation of AgNPs in low $\mathrm{MW} \mathrm{M}_{\mathrm{f}}$-NOM solution. The change of color and formation of precipitation is indicative of the aggregation and formation of larger AgNPs in the presence of $\mathrm{Ca}^{2+}$. In addition, the tint of AgNPs in lower MW $\mathrm{M}_{\mathrm{f}} \mathrm{NOM}$ solution changed more significantly than that in higher $\mathrm{MW} \mathrm{M}_{\mathrm{f}} \mathrm{NOM}$ solution, indicating high instability of AgNPs in lower $\mathrm{MW} \mathrm{M}_{\mathrm{f}}-\mathrm{NOM}$ solution. This assumption was further supported by the UV-vis spectra (Figure 4). With increasing $\mathrm{Ca}^{2+}$ concentration, the wavelength of the SPR peak shifted to the red-region and the peak intensity decreased. Comparably, the impact of $\mathrm{Ca}^{2+}$ coexisting with high $\mathrm{MW} \mathrm{M}_{\mathrm{f}} \mathrm{NOM}$ on AgNPs formation was not significant than that with low one. The TEM image (Figure 5) further confirmed the result of the UV-vis observation. The AgNPs in the $>100 \mathrm{kDa}$ fraction was still well dispersed in 30 $\mathrm{mg} \mathrm{L}^{-1} \mathrm{Ca}^{2+}$ (Figure $5 \mathrm{~b}$ ). However, significant aggregation of AgNPs, especially larger AgNPs, was observed in pristine NOM and $<3 \mathrm{kDa}$ fraction solution (Figure $5 \mathrm{a}, \mathrm{c}$, and $\mathrm{d}$ ). Figure $5 \mathrm{~d}$ also highlights an oriented attachment between two adjacent nanoparticles. The abundance of larger AgNPs ( $20 \mathrm{~nm}$ size) in pristine and $<3 \mathrm{kDa} \mathrm{NOM}$ was much higher than that in $>100 \mathrm{kDa} \mathrm{M}_{\mathrm{f}} \mathrm{NOM}$. In addition, AgNPs over $100 \mathrm{~nm}$ in size 

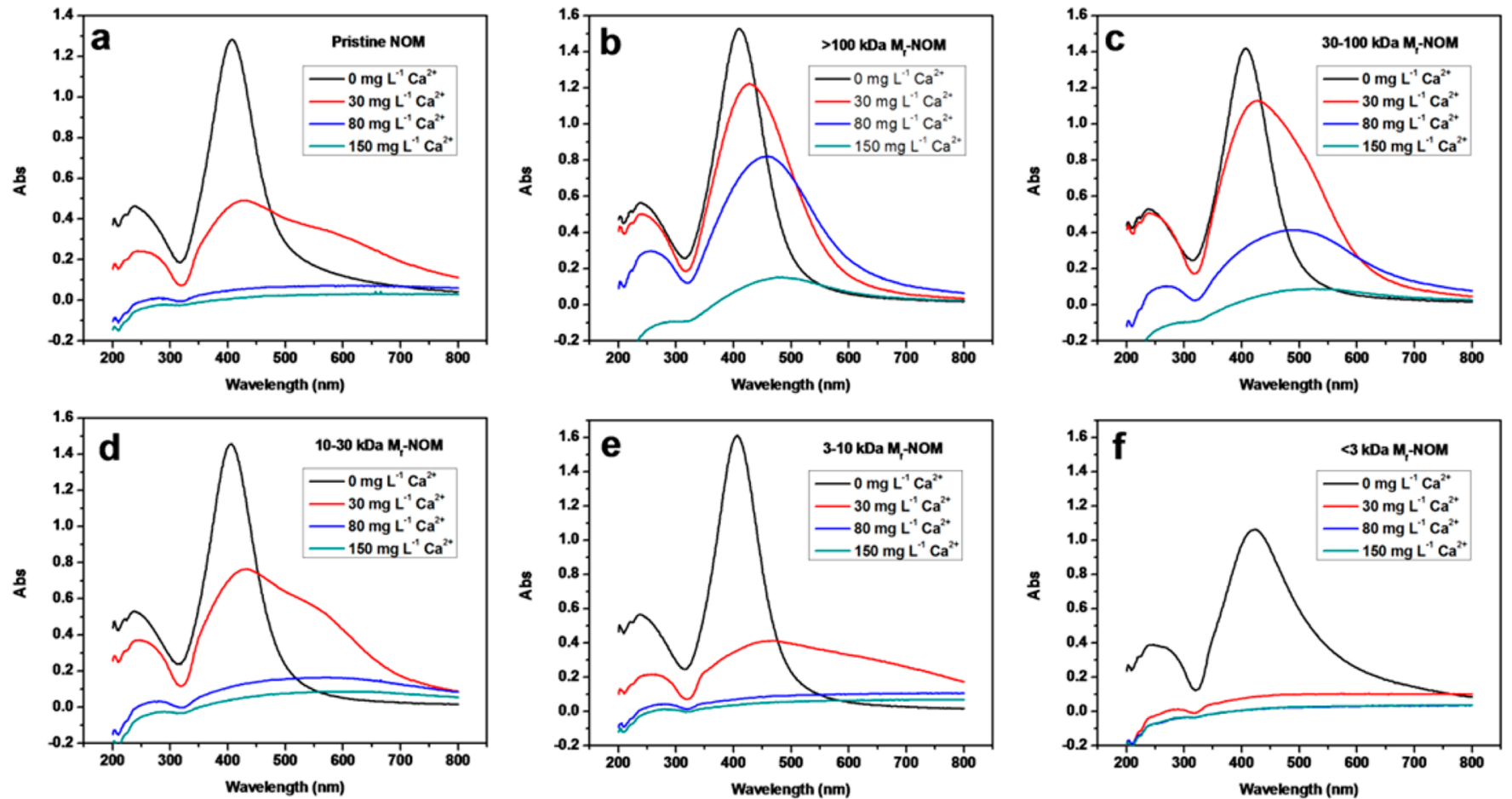

Figure 4. Impact of $\mathrm{Ca}^{2+}$ on UV-vis spectra of AgNPs formed in pristine and $\mathrm{M}_{\mathrm{f}}-\mathrm{NOM}$ under simulated sunlight. (a) pristine $\mathrm{NOM}$, (b) $>100 \mathrm{kDa}$ $\mathrm{M}_{\mathrm{f}} \mathrm{NOM}$, (c) 30-100 kDa M $\mathrm{f}_{\mathrm{f}} \mathrm{NOM}$, (d) 10-30 kDa $\mathrm{M}_{\mathrm{f}} \mathrm{NOM}$, (e) 3-10 kDa $\mathrm{M}_{\mathrm{f}} \mathrm{NOM}$, and (f) $<3 \mathrm{kDa} \mathrm{M}_{\mathrm{f}}-\mathrm{NOM}$. Background absorption of NOM was deducted from the prepared AgNPs solution. Solution conditions: $0.2 \mathrm{mmol} \mathrm{L}^{-1} \mathrm{AgClO}_{4}$ and $5 \mathrm{mg} \mathrm{L}{ }^{-1} \mathrm{DOC}_{\text {pristine or M }}-\mathrm{NOM} \mathrm{in}$ mmol L ${ }^{-1}$ borate buffer ( $\mathrm{pH} 8.0$ ) with $0,30,80,150 \mathrm{mg} \mathrm{L}^{-1} \mathrm{Ca}^{2+}\left(\right.$ as $\left.\mathrm{Ca}\left(\mathrm{ClO}_{4}\right)_{2}\right)$, respectively.

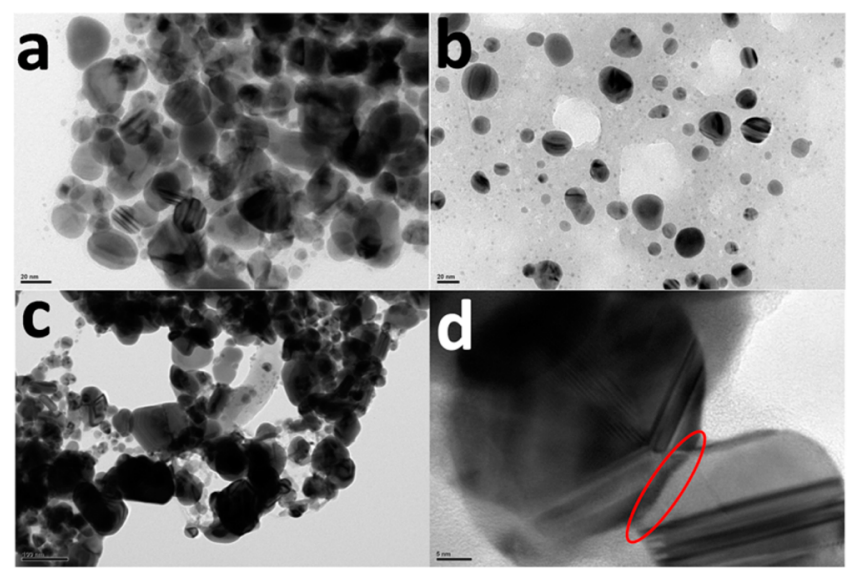

Figure 5. TEM images of AgNPs photosynthesized in pristine NOM (a), $>100 \mathrm{kDa} \mathrm{M}_{\mathrm{f}}-\mathrm{NOM}(\mathrm{b})$ and $<3 \mathrm{kDa} \mathrm{M}_{\mathrm{f}} \mathrm{NOM}$ ( $\mathrm{c}$ and d) in the presence of $30 \mathrm{mg} \mathrm{L}^{-1} \mathrm{Ca}^{2+}$. The scale bars are $20 \mathrm{~nm}, 20 \mathrm{~nm}, 100 \mathrm{~nm}$, and $5 \mathrm{~nm}$ for (a), (b), (c), and (d), respectively. Reaction conditions: $0.2 \mathrm{mmol} \mathrm{L}^{-1} \mathrm{AgClO}_{4}, 5 \mathrm{mg} \mathrm{L}{ }^{-1}$ DOC pristine or $\mathrm{M}_{\mathrm{f}} \mathrm{NOM}, 30 \mathrm{mg}$ $\mathrm{L}^{-1} \mathrm{Ca}^{2+}, 5 \mathrm{mmol} \mathrm{L}^{-1}$ borate buffer ( $\left.\mathrm{pH} 8.0\right)$ under simulated sunlight for $29 \mathrm{~h}$

were observed in $<3 \mathrm{kDa} \mathrm{M}_{\mathrm{f}} \mathrm{NOM}$ solution. UltrafiltrationICP-MS revealed that the percent of $\mathrm{Ag}^{+}$in total $\mathrm{Ag}$ in the photoirradiated solution increased from $\sim 20 \%$ (without $\mathrm{Ca}^{2+}$ ) to $\sim 40 \%$ with $150 \mathrm{mg} \mathrm{L}^{-1} \mathrm{Ca}^{2+}$, indicating $\mathrm{Ca}^{2+}$ may inhibit the reduction of $\mathrm{Ag}^{+}$to AgNPs by NOM. SI Figure S17 shows that the co-occurrence of $150 \mathrm{mg} \mathrm{L}^{-1} \mathrm{Ca}^{2+}$ slightly increased the light absorption of NOM in the wavelength from 250 to 500 $\mathrm{nm}$, indicating an interaction between $\mathrm{Ca}^{2+}$ and NOM. The decreasing reduction of $\mathrm{Ag}^{+}$to $\mathrm{AgNPs}$ by $\mathrm{Ca}^{2+}$ might be ascribed to the competitive binding of NOM by $\mathrm{Ag}^{+}$and $\mathrm{Ca}^{2+}$ and suggest that the binding of $\mathrm{Ag}^{+}$to $\mathrm{NOM}$ plays an important role in this reduction process.

Electrostatic and steric stabilization provided by NOM adsorbed on the surfaces of AgNPs may prevent aggregation. ${ }^{50}$ This dispersion effect of NOM on AgNPs could inhibit the fusion-induced growth of AgNPs. In the presence of $\mathrm{Ca}^{2+}$, increasing aggregation was observed with decreasing MWs of NOM, possibly due to different interactions between $\mathrm{M}_{\mathrm{f}} \mathrm{NOM}$ with varying MWs and nanoparticles. ${ }^{30}$ The aggregation of AgNPs induced by $\mathrm{Ca}^{2+}$ could reduce the distance between AgNPs and consequently fuse "old" small AgNPs to "new" larger AgNPs with the reduction of $\mathrm{Ag}^{+}$to elemental $\mathrm{Ag}$ between adjacent "old" AgNPs. This assumption is supported by a TEM image of AgNPs in $<3 \mathrm{kDa}$ fraction (Figure $5 \mathrm{~d}$ ), where we observe larger AgNPs formation through aggregation and oriented-attachment-fusion of smaller AgNPs.

Comparison of Photo- and Heat-induced Reduction of $\mathrm{Ag}^{+}$to AgNPs. The heat-induced reduction of $\mathrm{Ag}^{+}$to AgNPs by pristine NOM and $\mathrm{M}_{\mathrm{f}} \mathrm{NOM}$ was also investigated at $4{ }^{\circ} \mathrm{C}$, room temperature $\left(\sim 25^{\circ} \mathrm{C}\right.$, data not shown $), 45^{\circ} \mathrm{C}$, and $60{ }^{\circ} \mathrm{C}$ (SI Figure S18). At $4{ }^{\circ} \mathrm{C}$, no formation of AgNPs was observed in $35 \mathrm{~h}$. With increasing incubation temperature, no significant effect on the size of the AgNPs was observed, and the formation rate of AgNPs increased markedly. When comparing the effects of heating with light irradiation for AgNPs formation, we find that heat-induced AgNPs have a much narrower half peak width and homogeneous size distribution compared to photoinduced AgNPs. Under light irradiation, oscillation of electrons at resonant conditions resulted in a nonuniform surface charge distribution in AgNPs and the creation of an oscillating dipole. ${ }^{51}$ This dipole-dipole attraction between particles was strong enough to drive the aggregation of nanoparticles. ${ }^{52}$ The aggregation of 
small AgNPs and further reduction $\mathrm{Ag}^{+}$to $\mathrm{Ag}^{0}$ could induce the fusion and growth of nanoparticles and result in formation of larger AgNPs. Therefore, the photo- and heat-induced AgNPs result in varying size-distribution patterns. The TEM images (SI Figure S19) show a comparison of AgNPs in $>100 \mathrm{kDa} \mathrm{M}_{\mathrm{f}}$ NOM solution and those in $<3 \mathrm{kDa} \mathrm{M}_{\mathrm{f}} \mathrm{NOM}$ solution, indicating that the $<3 \mathrm{kDa} \mathrm{M}_{\mathrm{f}} \mathrm{NOM}$ solution contains larger and more polydispersed AgNPs and suggesting varying stabilization capabilities of $\mathrm{M}_{\mathrm{f}}-\mathrm{NOM}$ on AgNPs with heating.

Environmental Implications. Findings in this study reveal that different $\mathrm{M}_{\mathrm{f}} \mathrm{NOM}$ show differential photoreduction activity toward $\mathrm{Ag}^{+}$and has significantly different effects on the stability of photoinduced AgNPs against aggregation in the presence of $\mathrm{Ca}^{2+}$. Factors considered in this study, including simulated sunlight, heating, and other parameters $(\mathrm{pH}, \mathrm{DOM}$ concentration, $\mathrm{Ca}^{2+}$ concentration), are environmentally relevant, suggesting that the differential roles of $\mathrm{M}_{\mathrm{f}}-\mathrm{NOM}$ on photoreduction and stabilization in transformation $\mathrm{of}^{+}$to AgNPs may have significant implications in real environments. As environmental waters with different origins could have different DOC concentrations, NOM MW distributions, and chemical compositions, the photoreduction of $\mathrm{Ag}^{+}$to $\mathrm{AgNPs}$ in these aquatic environments may be highly site-specific. For example, in DOM-rich blackish water, the effects of light attenuation could decrease the photoreduction of $\mathrm{Ag}^{+}$ significantly. Furthermore, this difference might also have drastic impacts on the transport, adsorption, and sedimentation of the photoinduced AgNPs in the aquatic environment. The selective adsorption of $\mathrm{M}_{\mathrm{f}}-\mathrm{NOM}$ on minerals could also change the MW distribution of NOM in natural waters, ${ }^{53,54}$ which could further influence the dispersion and aggregation of AgNPs. Considering the drastic difference of $\mathrm{M}_{\mathrm{f}} \mathrm{NOM}$ in the photoreduction of $\mathrm{Ag}^{+}$to AgNPs and the stabilization of the photosynthesized AgNPs, especially in the presence of $\mathrm{Ca}^{2+}$, further studies are strongly suggested to reveal the roles of $\mathrm{M}_{\mathrm{f}}$ NOM in the stabilization of engineered AgNPs and their effects on the phototransformation of engineered AgNPs in sunlit water under environmental conditions.

\section{ASSOCIATED CONTENT}

\section{S Supporting Information}

Additional results are provided in Supporting Information. This material is available free of charge via the Internet at http:// pubs.acs.org.

\section{AUTHOR INFORMATION}

\section{Corresponding Author}

*Phone: +86-10-62849192; fax: +86-10-62849192; e-mail: jfliu@rcees.ac.cn.

\section{Notes}

The authors declare no competing financial interest.

\section{ACKNOWLEDGMENTS}

This work was supported by the Strategic Priority Research Program of the Chinese Academy of Sciences (XDB14020101), the National Natural Science Foundation of China (21025729, 21337004, and 21207124), and Young Scientists Fund of RCEES (RCEES-QN-20130028F). We thank Miss Mingfang Wang in the Beijing National Center for Electron Microscopy for TEM characterizations and Dr. Yanbin $\mathrm{Li}$ from Ocean University of China for providing the UV and mylar film and discussion on this work. Dr. Adina Chuang Howe from
Michigan State University is thanked for enhancing the quality of English of this paper. The authors would also like to express their sincere thanks to the anonymous reviewers for their valuable comments and suggestions on this paper.

\section{REFERENCES}

(1) Project on Emerging Nanotechnologies, 2014\, Consumer Products Inventory. http://www.nanotechproject.org/cpi (accessed 4/10/2014).

(2) Reidy, B.; Haase, A.; Luch, A.; Dawson, K. A.; Lynch, I. Mechanisms of silver nanoparticle release, transformation and toxicity: A critical review of current knowledge and recommendations for future studies and applications. Materials 2013, 6, 2295-2350.

(3) Benn, T.; Cavanagh, B.; Hristovski, K.; Posner, J. D.; Westerhoff, $\mathrm{P}$. The release of nanosilver from consumer products used in the home. J. Environ. Qual. 2010, 39, 1875-1882.

(4) Benn, T. M.; Westerhoff, P. Nanoparticle silver released into water from commercially available sock fabrics. Environ. Sci. Technol. 2008, 42, 4133-4139.

(5) Kaegi, R.; Sinnet, B.; Zuleeg, S.; Hagendorfer, H.; Mueller, E.; Vonbank, R.; Boller, M.; Burkhardt, M. Release of silver nanoparticles from outdoor facades. Environ. Pollut. 2010, 158 (9), 2900-2905.

(6) Quadros, M. E.; Marr, L. C. Silver nanoparticles and total aerosols emitted by nanotechnology related consumer spray products. Environ. Sci. Technol. 2011, 45, 10713-10719.

(7) Quadros, M. E.; Pierson, R.; Tulve, N. S.; Willis, R.; Rogers, K.; Thomas, T. A.; Marr, L. C. Release of silver from nanotechnologybased consumer products for children. Environ. Sci. Technol. 2013, 47, 8894-8901

(8) Levard, C.; Hotze, E. M.; Lowry, G. V.; Brown, G. E. Environmental transformations of silver nanoparticles: Impact on stability and toxicity. Environ. Sci. Technol. 2012, 46, 6900-6914.

(9) Wiesner, M. R.; Lowry, G. V.; Casman, E.; Bertsch, P. M.; Matson, C. W.; Di Giulio, 1 R. T.; Liu, J.; Hochella, M. F. Meditations on the ubiquity and mutability of nano-sized materials in the environment. ACS Nano 2011, 5, 8466-8470.

(10) Glover, R. D.; Miller, J. M.; Hutchison, J. E. Generation of metal nanoparticles from silver and copper objects: Nanoparticle dynamics on surfaces and potential sources of nanoparticles in the environment. ACS Nano 2011, 5, 8950-8957.

(11) Yu, S. J.; Yin, Y. G.; Chao, J. B.; Shen, M. H.; Liu, J. F. Highly dynamic PVP-coated silver nanoparticles in aquatic environments: Chemical and morphology change induced by oxidation of $\mathrm{Ag}^{0}$ and reduction of $\mathrm{Ag}^{+}$. Environ. Sci. Technol. 2014, 48, 403-411.

(12) Li, Y.; Zhang, W.; Niu, J. F.; Chen, Y. S. Surface-coatingdependent dissolution, aggregation, and reactive oxygen species (ROS) generation of silver nanoparticles under different irradiation conditions. Environ. Sci. Technol. 2013, 47, 10293-10301.

(13) Liu, J.; Sonshine, D. A.; Shervani, S.; Hurt, R. H. Controlled release of biologically active silver from nanosilver surfaces. ACS Nano 2010, 4, 6903-6913.

(14) Zhao, C. M.; Wang, W. X. Size-dependent uptake of silver nanoparticles in Daphnia magna. Environ. Sci. Technol. 2012, 46, 11345-11351.

(15) Liu, W.; Wu, Y.; Wang, C.; Li, H. C.; Wang, T.; Liao, C. Y.; Cui, L.; Zhou, Q. F.; Yan, B.; Jiang, G. B. Impact of silver nanoparticles on human cells: Effect of particle size. Nanotoxicology 2010, 4, 319-330.

(16) Xiu, Z. M.; Zhang, Q. B.; Puppala, H. L.; Colvin, V. L.; Alvarez, P. J. J. Negligible particle-specific antibacterial activity of silver nanoparticles. Nano Lett. 2012, 12, 4271-4275.

(17) Akaighe, N.; MacCuspie, R. I.; Navarro, D. A.; Aga, D. S.; Banerjee, S.; Sohn, M.; Sharma, V. K. Humic acid-induced silver nanoparticle formation under environmentally relevant conditions. Environ. Sci. Technol. 2011, 45, 3895-3901.

(18) Yin, Y. G.; Liu, J. F.; Jiang, G. B. Sunlight-induced reduction of ionic $\mathrm{Ag}$ and $\mathrm{Au}$ to metallic nanoparticles by dissolved organic matter. ACS Nano 2012, 6, 7910-7919. 
(19) Adegboyega, N. F.; Sharma, V. K.; Siskova, K.; Zboril, R.; Sohn, M.; Schultz, B. J.; Banerjee, S. Interactions of aqueous $\mathrm{Ag}^{+}$with fulvic acids: Mechanisms of silver nanoparticle formation and investigation of stability. Environ. Sci. Technol. 2013, 47, 757-764.

(20) Hou, W.-C.; Stuart, B.; Howes, R.; Zepp, R. G. Sunlight-driven reduction of silver ions by natural organic matter: Formation and transformation of silver nanoparticles. Environ. Sci. Technol. 2013, 47, $7713-7721$.

(21) Juganson, K.; Mortimer, M.; Ivask, A.; Kasemets, K.; Kahru, A. Extracellular conversion of silver ions into silver nanoparticles by protozoan Tetrahymena thermophila. Environ. Sci.: Processes Impacts 2013, 15, 244-250.

(22) Kang, F. X.; Alvarez, P. J.; Zhu, D. Q. Microbial extracellular polymeric substances reduce $\mathrm{Ag}^{+}$to silver nanoparticles and antagonize bactericidal activity. Environ. Sci. Technol. 2014, 48, 316322.

(23) Rose, A. L.; Waite, D. Role of superoxide in the photochemical reduction of iron in seawater. Geochim. Cosmochim. Acta 2006, 70 (15), 3869-3882.

(24) Jones, A. M.; Garg, S.; He, D.; Pham, A. N.; Waite, T. D. Superoxide-mediated formation and charging of silver nanoparticles. Environ. Sci. Technol. 2011, 45 (4), 1428-1434.

(25) Mostofa, K. M. G.; Liu, C. Q.; Mottaleb, M. A.; Wan, G. J.; Ogawa, H.; Vione, D.; Yoshioka, T.; Wu, F. C. Dissolved organic matter in natural waters. In Photobiogeochemistry of Organic Matter: Principles and Practices in Water Environments; Mostofa, K. M. G.; Yoshioka, T.; Mottaleb, M. A.; Vione, D., Eds.; Springer, 2013.

(26) Richard, C.; Guyot, G.; Rivaton, A.; Trubetskaya, O.; Trubetskoj, O.; Cavani, L.; Ciavatta, C. Spectroscopic approach for elucidation of structural peculiarities of Andisol soil humic acid fractionated by SEC-PAGE setup. Geoderma 2007, 142 (1-2), 210216.

(27) Falzoni, A.; Seeber, R.; Tonelli, D.; Ciavatta, C.; Gessa, C.; Montecchio, D. Dependence on molecular weight of acid-base properties of humic and fulvic acids. Analusis 1998, 26 (5), 214-219.

(28) Ohno, T.; Chorover, J.; Omoike, A.; Hunt, J. Molecular weight and humification index as predictors of adsorption for plant- and manure-derived dissolved organic matter to goethite. Eur. J. Soil Sci. 2007, 58, 125-132.

(29) Chen, G. A.; Lin, C.; Chen, L. A.; Yang, H. Effect of sizefractionation dissolved organic matter on the mobility of prometryne in soil. Chemosphere 2010, 79 (11), 1046-1055.

(30) Louie, S. M.; Tilton, R. D.; Lowry, G. V. Effects of molecular weight distribution and chemical properties of natural organic matter on gold nanoparticle aggregation. Environ. Sci. Technol. 2013, 47, $4245-4254$.

(31) Dong, M. M.; Mezyk, S. P.; Rosario-Ortiz, F. L. Reactivity of effluent organic matter (EfOM) with hydroxyl radical as a function of molecular weight. Environ. Sci. Technol. 2010, 44, 5714-5720.

(32) Kitis, M.; Karanfil, T.; Wigton, A.; Kilduff, J. E. Probing reactivity of dissolved organic matter for disinfection by-product formation using XAD-8 resin adsorption and ultrafiltration fractionation. Water Res. 2002, 36 (15), 3834-3848.

(33) Chen, S. Y.; Huang, S. W.; Chiang, P. N.; Liu, J. C.; Kuan, W. H.; Huang, J. H.; Hung, J. T.; Tzou, Y. M.; Chen, C. C.; Wang, M. K. Influence of chemical compositions and molecular weights of humic acids on $\mathrm{Cr}(\mathrm{VI})$ photo-reduction. J. Hazard. Mater. 2011, 197, 337344.

(34) Aguer, J. P.; Trubetskaya, O.; Trubetskoj, O.; Richard, C. Photoinductive properties of soil humic acids and their fractions obtained by tandem size exclusion chromatography-polyacrylamide gel electrophoresis. Chemosphere 2001, 44 (2), 205-209.

(35) Richard, C.; Trubetskaya, O.; Trubetskoj, O.; Reznikova, O.; Afanas'eva, G.; Aguer, J. P.; Guyot, G. Key role of the low molecular size fraction of soil humic acids for fluorescence and photoinductive activity. Environ. Sci. Technol. 2004, 38 (7), 2052-2057.

(36) Meunier, L.; Laubscher, H.; Hug, S. J.; Sulzberger, B. Effects of size and origin of natural dissolved organic matter compounds on the redox cycling of iron in sunlit surface waters. Aquat. Sci. 2005, 67 (3), 292-307.

(37) Hartmann, G.; Hutterer, C.; Schuster, M. Ultra-trace determination of silver nanoparticles in water samples using cloud point extraction and ETAAS. J. Anal. Atom. Spectrom. 2013, 28 (4), $567-572$.

(38) Hartmann, G.; Baumgartner, T.; Schuster, M. Influence of particle coating and matrix constituents on the cloud point extraction efficiency of silver nanoparticles (Ag-NPs) and application for monitoring the formation of $\mathrm{Ag}-\mathrm{NPs}$ from $\mathrm{Ag}^{+}$. Anal. Chem. 2014, 86 (1), 790-796.

(39) Chappell, M. A.; Miller, L. F.; George, A. J.; Pettway, B. A.; Price, C. L.; Porter, B. E.; Bednar, A. J.; Seiter, J. M.; Kennedy, A. J.; Steevens, J. A. Simultaneous dispersion-dissolution behavior of concentrated silver nanoparticle suspensions in the presence of model organic solutes. Chemosphere 2011, 84 (8), 1108-1116.

(40) Zepp, R. G.; Schlotzhauer, P. F.; Sink, R. M. Photosensitized transformations involving electronic energy transfer in natural waters Role of humic substances. Environ. Sci. Technol. 1985, 19, 74-81.

(41) Peuravuori, J.; Pihlaja, K. Molecular size distribution and spectroscopic properties of aquatic humic substances. Anal. Chim. Acta 1997, 337 (2), 133-149.

(42) Coble, P. G. Characterization of marine and terrestrial DOM in seawater using excitation emission matrix spectroscopy. Mar. Chem. 1996, 51 (4), 325-346.

(43) Taubert, A.; Wiesler, U. M.; Mullen, K. Dendrimer-controlled one-pot synthesis of gold nanoparticles with a bimodal size distribution and their self-assembly in the solid state. J. Mater. Chem. 2003, 13 (5), 1090-1093.

(44) Yin, Y. G.; Yu, S. J.; Liu, J. F.; Jiang, G. B. Thermal and photoinduced reduction of ionic $\mathrm{Au}$ (III) to elemental Au nanoparticles by dissolved organic matter in water: Possible source of naturally occurring Au nanoparticles. Environ. Sci. Technol. 2014, 48, 26712679.

(45) Lin, X. Z.; Teng, X. W.; Yang, H. Direct synthesis of narrowly dispersed silver nanoparticles using a single-source precursor. Langmuir 2003, 19 (24), 10081-10085.

(46) Peng, S.; McMahon, J. M.; Schatz, G. C.; Gray, S. K.; Sun, Y. G. Reversing the size-dependence of surface plasmon resonances. Proc. Natl. Acad. Sci. U.S.A. 2010, 107 (33), 14530-14534.

(47) Atalay, Y. B.; Carbonaro, R. F.; Di Toro, D. M. Distribution of proton dissociation constants for model humic and fulvic acid molecules. Environ. Sci. Technol. 2009, 43 (10), 3626-3631.

(48) El Badawy, A. M.; Scheckel, K. G.; Suidan, M.; Tolaymat, T. The impact of stabilization mechanism on the aggregation kinetics of silver nanoparticles. Sci. Total Environ. 2012, 429, 325-331.

(49) Huynh, K. A.; Chen, K. L. Aggregation kinetics of citrate and polyvinylpyrrolidone coated silver nanoparticles in monovalent and divalent electrolyte solutions. Environ. Sci. Technol. 2011, 45 (13), 5564-5571.

(50) Lau, B. L. T.; Hockaday, W. C.; Ikuma, K.; Furman, O.; Decho, A. W. A preliminary assessment of the interactions between the capping agents of silver nanoparticles and environmental organics. Colloid. Surf., A 2013, 435, 22-27.

(51) Cheng, Y. W.; Yin, L. Y.; Lin, S. H.; Wiesner, M.; Bernhardt, E.; Liu, J. Toxicity reduction of polymer-stabilized silver nanoparticles by sunlight. J. Phys. Chem. C 2011, 115 (11), 4425-4432.

(52) Tang, Z. Y.; Kotov, N. A.; Giersig, M. Spontaneous organization of single $\mathrm{CdTe}$ nanoparticles into luminescent nanowires. Science 2002, 297 (5579), 237-240.

(53) Gu, B. H.; Schmitt, J.; Chen, Z.; Liang, L. Y.; Mccarthy, J. F. Adsorption and desorption of different organic-matter fractions on iron-oxide. Geochim. Cosmochim. Acta 1995, 59 (2), 219-229.

(54) Wang, L. L.; Chin, Y. P.; Traina, S. J. Adsorption of (poly)maleic acid and an aquatic fulvic acid by goethite. Geochim. Cosmochim. Acta 1997, 61 (24), 5313-5324. 